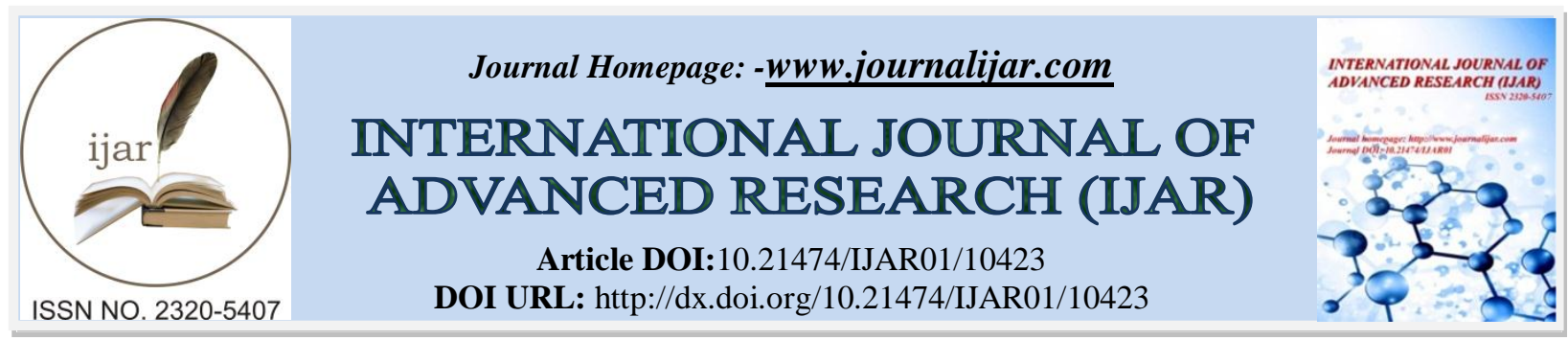

RESEARCH ARTICLE

\title{
AFFORDABLE FOOT PROSTHESIS MADE USING FIXIT SILICONE GIVING AMPUTEES A SECOND CHANCE USING PROSTHODONTICS LABORATORY TECHNIQUE
}

\author{
Dr. Elizabeth K., Dr. Suja Joseph, Dr. Aby Mathew T., Dr. Haby Mathew Somson, Dr. Shoma Sasidharan \\ and Dr. Veena Paul \\ Department Of Prosthodontics Pushpagiri College Of Dental Sciences.
}

\section{Manuscript Info}

Manuscript History

Received: 30 November 2019

Final Accepted: 31 December 2019

Published: January 2020

Key words:-

Chopart Amputation, Fixit

\section{Abstract}

Affordable foot prosthesis is a major aid for financially unsoundamputees.A female patient with partial foot amputation at midtarsal joint with a history of road accident came for prosthetic rehabilitation of the limb.Fixit silicone was used for foot prosthesisfabrication.Despite not being medical graded silicone,patient is satisified with its limited function,biocompatibility and esthetics.Patient is reviewed after one month.

Copy Right, IJAR, 2020,. All rights reserved.

\section{Introduction:-}

\section{Case Report:}

A 60 year old female patient came to our Department of Prosthodontics with amputated right forefoot at midtarsaljoint.Amputation was done following an accident which occurred 8 years ago .Choparts amputation is the separation of forefoot at the midtarsaljoint.It offers an advantage of retaining ankle motion in comparison with other higher level amputations.On examination a healing ulcer was found on the mid part of the sole area.It was planned to fabricate a silicone prosthesis at an affordable price using fixit silicone to restore esthetics and function.Patient primary concern was to be able to stand independenly for her daily routine activities. We explained the treatment plans and she gave her consent for silicone prosthesis though not medically graded

\section{Step By Step Fabrication Of The Silicone Prosthesis:}

Impression Making:Boththe right and left affected and unaffected leg were cleaned usingbetadiene .Impression of the amputated leg was made using irreversible hydrocolloid as per the instructions given by the manufacturer(Zhermack,Tropicalgin Alginate Normal).Cotton gauze was placed all over the alginate impression so as to provide a mechanical interlocking between the alginate and plaster.Once the alginate was set,thick plaster mix was poured over it to reinforce the whole unit.Following setting it was removed from the leg and Plaster of Paris was poured into the impression of the amputated leg to get master cast free of voids and defects (Fig2).Measurement of the left foot of the patient was found to be $10 \mathrm{~mm}$ lenth and $13 \mathrm{~mm}$ width.Impression of a similar right leg with same measurement was taken from another person inorder to make a wax pattern trial(Fig 3).

Wax Pattern Trial:After making a wax pattern ,it was inserted into the patients amputated leg to check whether it resembled the other leg in size,shape and form(Fig 4).Shade matching was done and the foot was shaped according to the patient's left leg.After the wax trial,wax waswell adapted to the master cast and a plaster mould was made over the wax pattern adapted over the master cast(Fig 5).Sectional plaster mould was made so that the opening and retrieval of the silicone prosthesis would be easier.Dewaxingwas done inorder to obtain a hollow space to fill the silicone material(Fig 6). 
Fabrication of silicone prosthesis:Afterdewaxing,separating medium was applied throughout the mould cavity.Oil colour(Burnt sienna,white and pinch of black)was used to give a similar skin shade for the prosthesis.3 tubes of Fixit silicone sealant were used simultaneously and the colour was added into it to get a uniform shade and consistency.Mould space was filled with silicone material and the assembly was tightly packed and wrapped.The setting time of fixitsilicone is $15 \mathrm{~min}$ as per the manufacturer(Fig 7).After opening the mould sectionally,theprosthesis was retrieved and the excess material was removed(Fig 8).Toes were separated and nail colours were applied.Foot wear was custom made to accommodate the amputated foot and the silicone prosthesis(Fig 9).

The retention of the prosthesis is mainly by attachment of the foot prosthesis with the foot wears so that the sandals willnot slip away from the prosthesis thereby improving the retention by the close approximation of the silicone prosthesis with the amputated foot.

\section{Discussion:-}

Infection with tissue necrosis in diabetic patients, gangrene, ischemia due to peripheral disease,traumaare causes of concern which leads to amputation of the affected leg.Partial foot amputation provide an advantage of retention of plantar load bearing tissues which allow the patient to ambulate with or without prosthesis.Silicone material we used is Fixit Silicone sealant which is normally used for household purpose and we checked if patient has any allergic issues with this silicone sealant before prosthesis fabrication The main goal of prosthetic management of patient with limb loss is to restore function,form and restore self reliance for the patient.Different types of amputations include toe amputation, rayamputation, Transmetatarsalamputations, Lisfranc's amputations, syme'sampuataions, chopart'samputations. Several options are available for chopart's amputee but most of the prosthesis take support at or above the ankle.This disarticulation occur through the talonavicular and calcaneo cuboid joints. The main aim of prosthetic rehabilitataion in chopartsamputataion is to prevent deformity,provide anterior support and cosmetic restoration.Managment of choparts amputation include AFO with filler,modifiedSMO,Carbon fibre foot plates,Chopart plate by endolite,chopart plate by ottobock,High definition silicone foot(HDSF),custom made silicone foot etc. The major flaw of the below ankle design is that it lacks an effective lever arm that would help to lift the partial foot.In this case, we used fixit silicone sealant which is less flexible than the medical graded silicone and the custom made foot wear is used so that the length of the leg can be adjusted.The silicone we used in this study has not been used earlier for similar situations.

Hydrophobic nature of well adapted silicone not only protects the wound but also improves the psychological well being of the patient.Even if the silicone material is flexible, lightin weight, the attachment of the foot wear with the prosthesis increased its weight.However limited it is in function, the patient seems to be patient compliant.

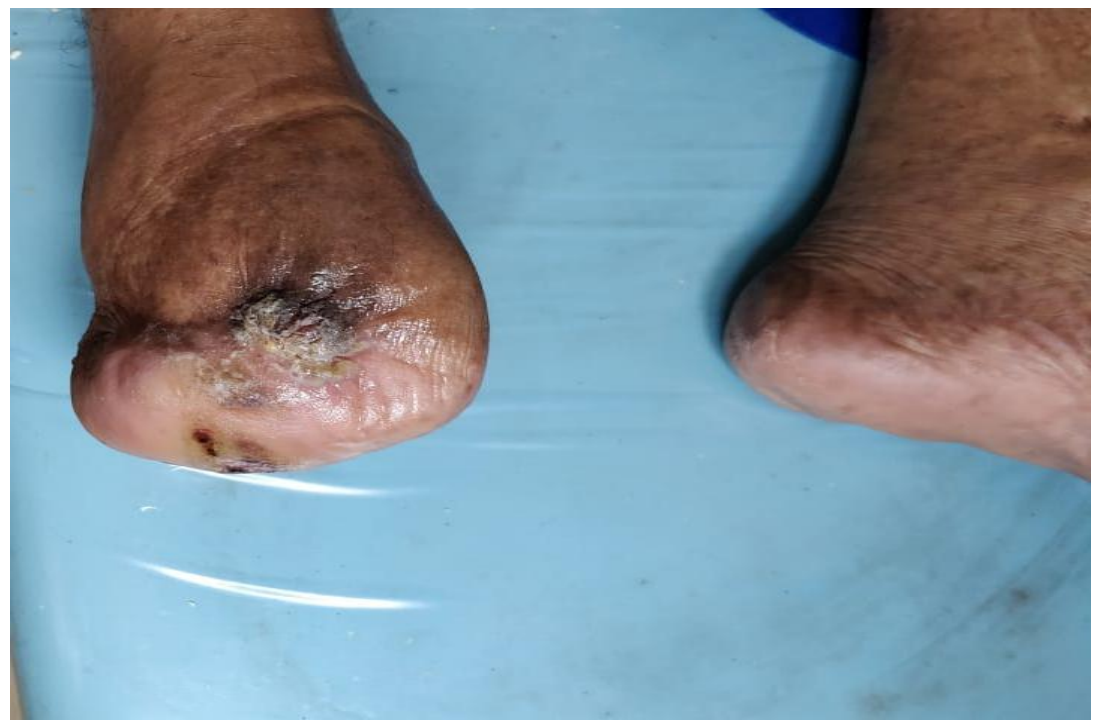

Fig 1:- Amputed Leg. 


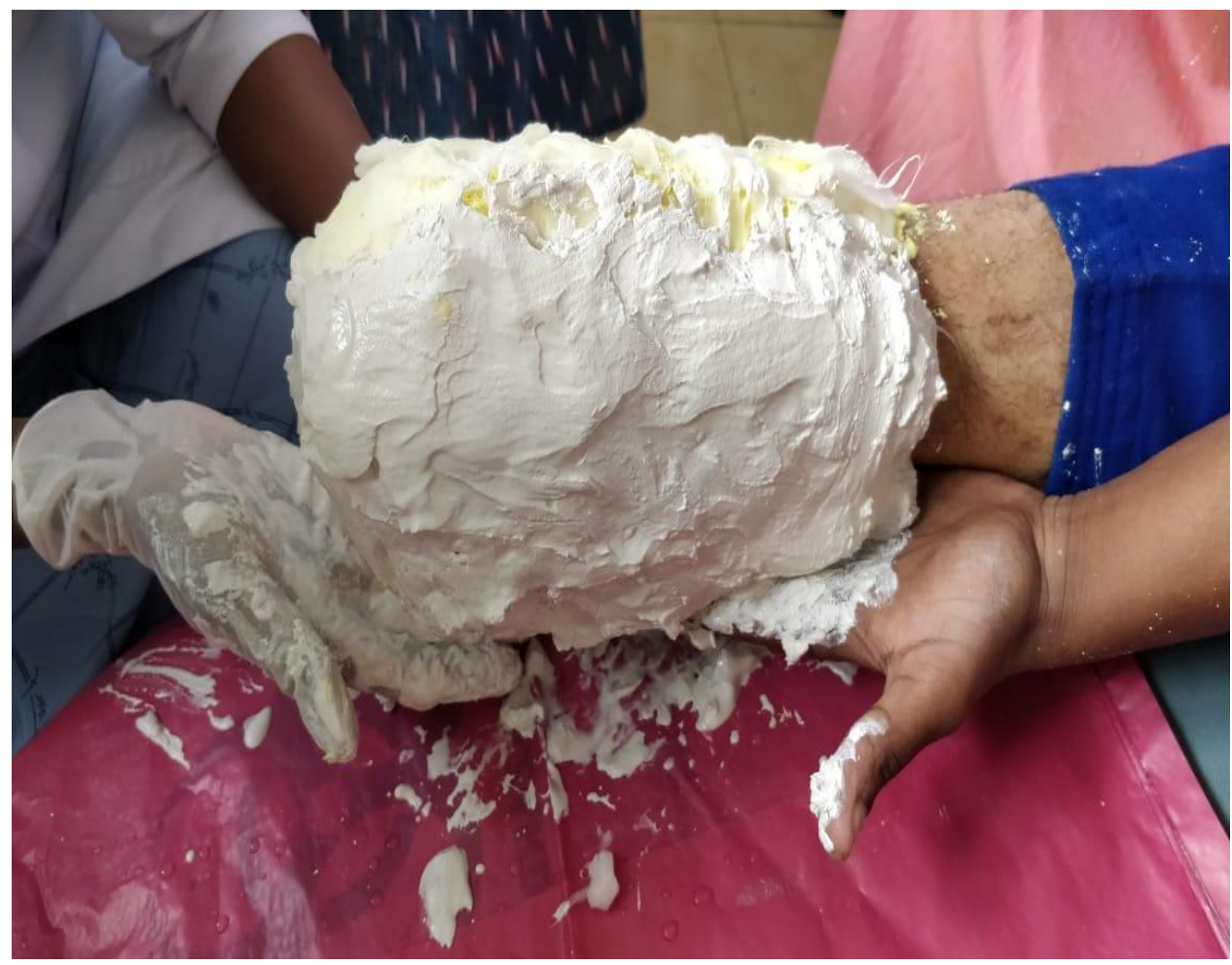

Fig 2:- Impression Making.

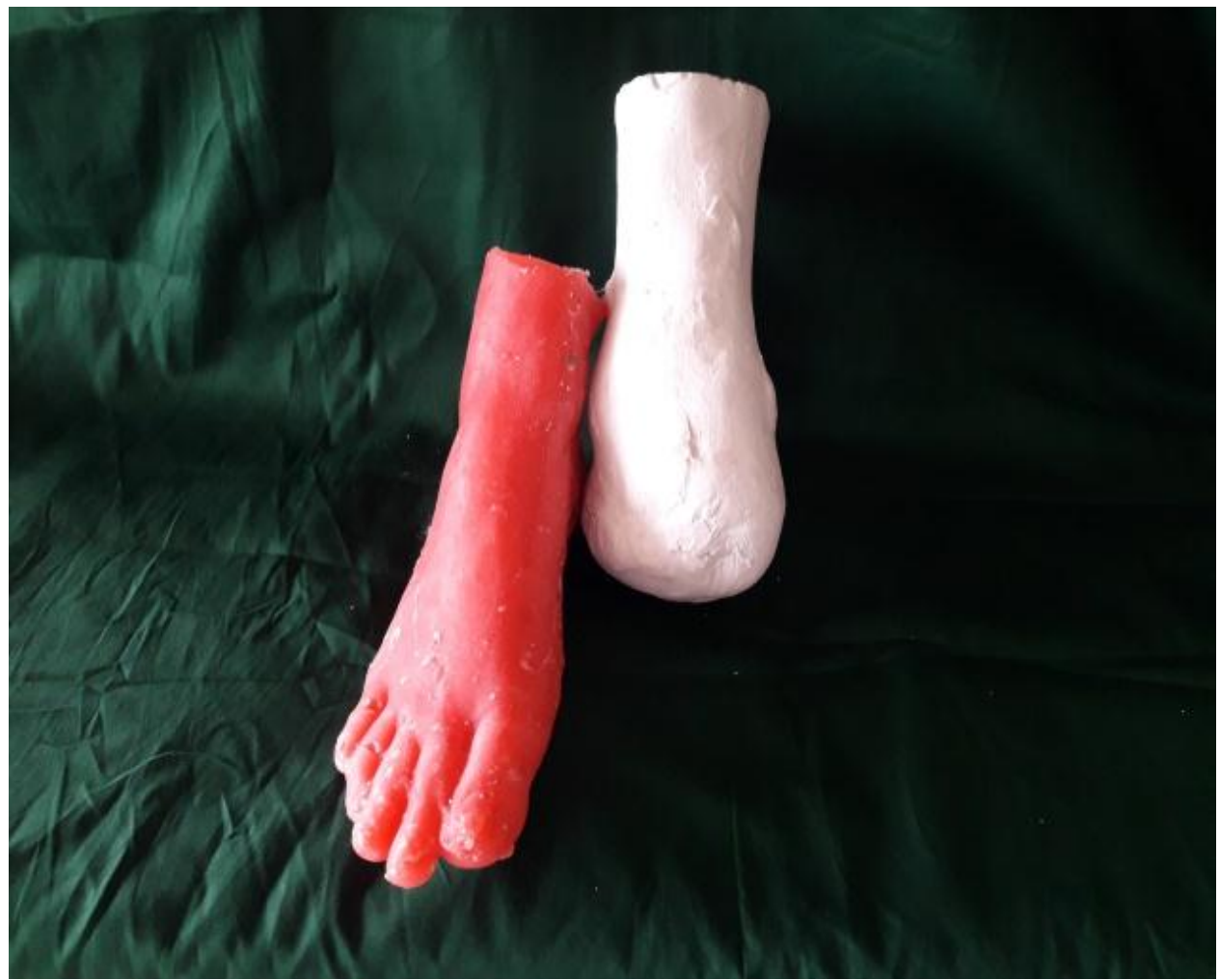

Fig 3:- Master Cast With Wax Pattern. 


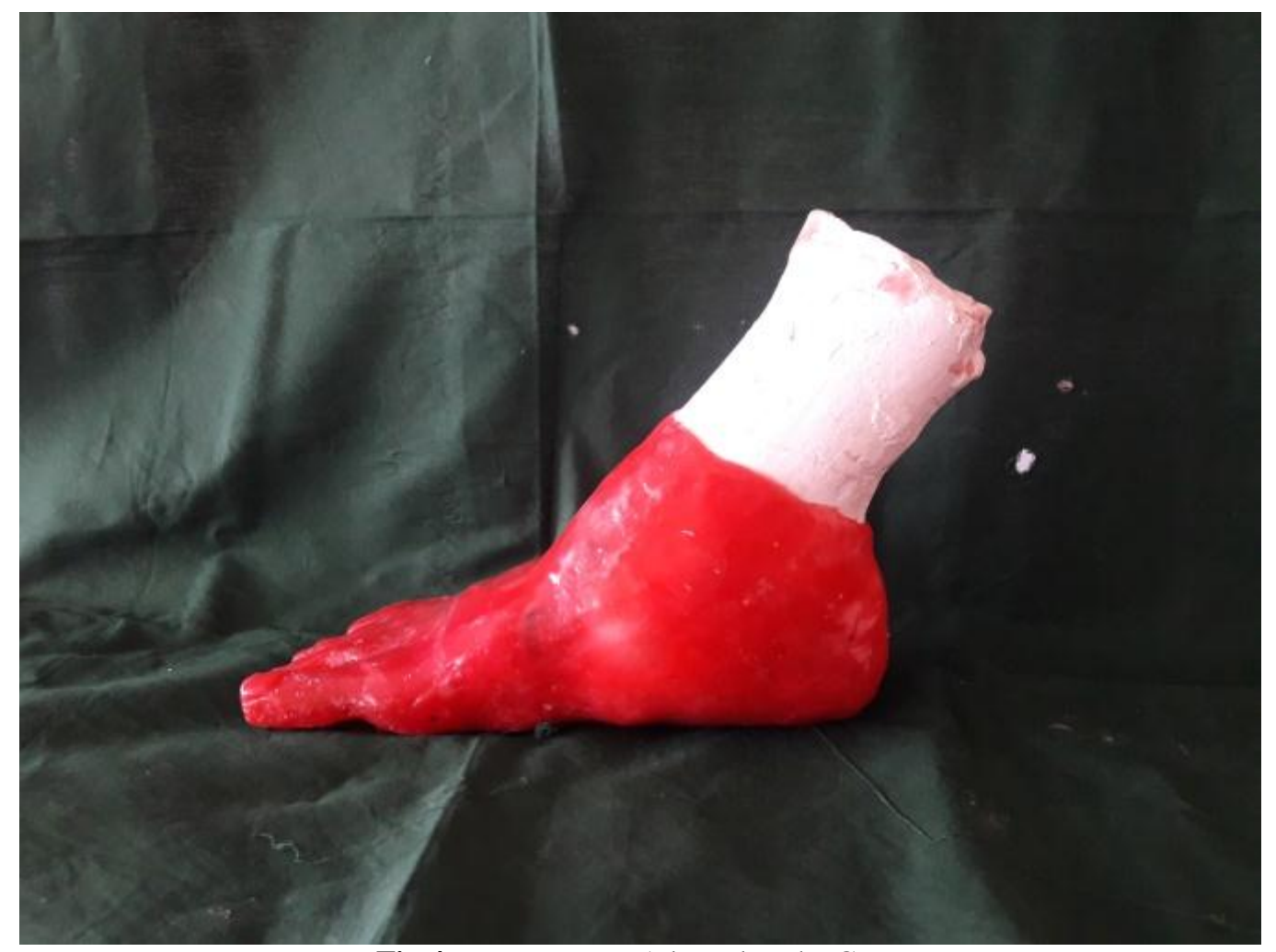

Fig 4:- Wax pattern Adapted to the Cast.

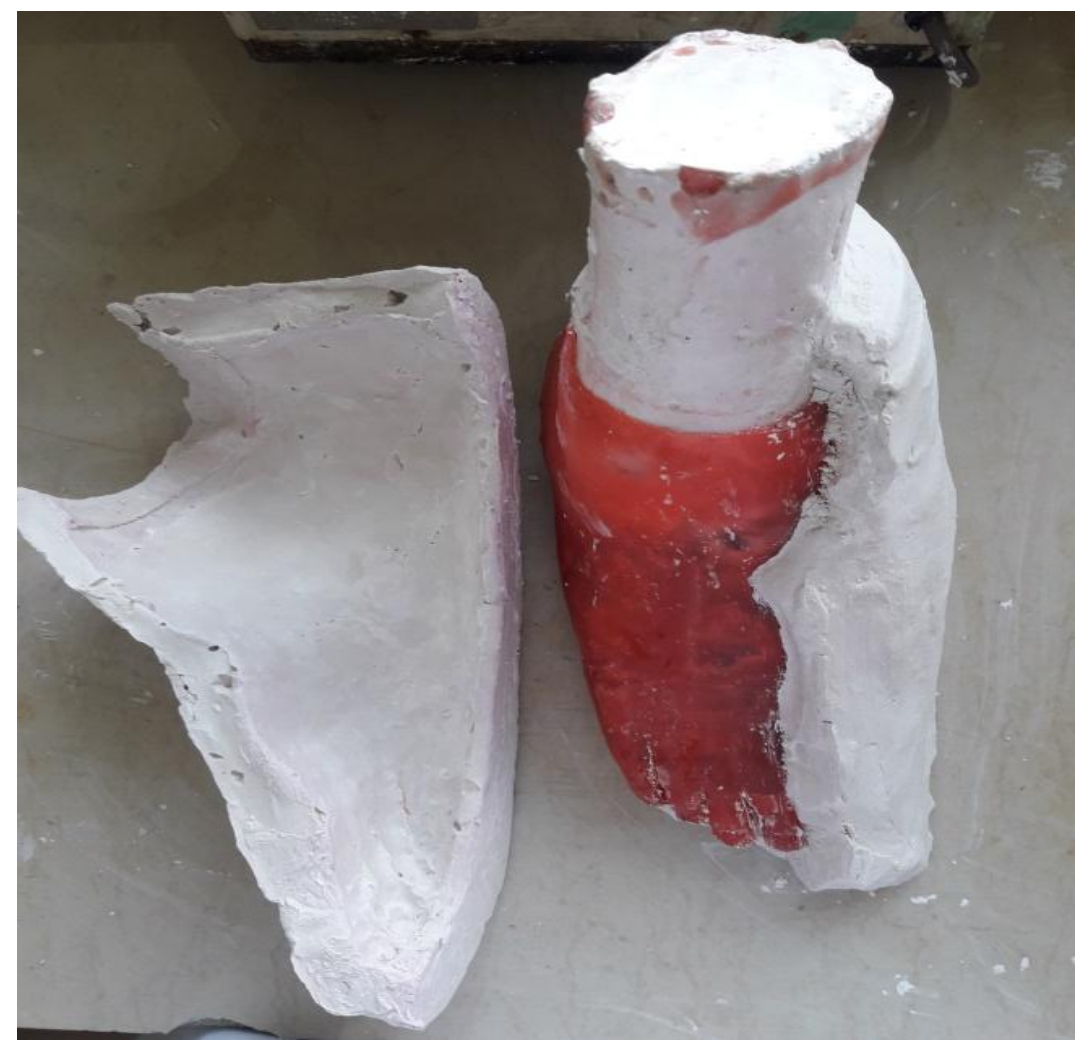

Fig 5:- Plaster mould made over the Wax Pattern Trial. 


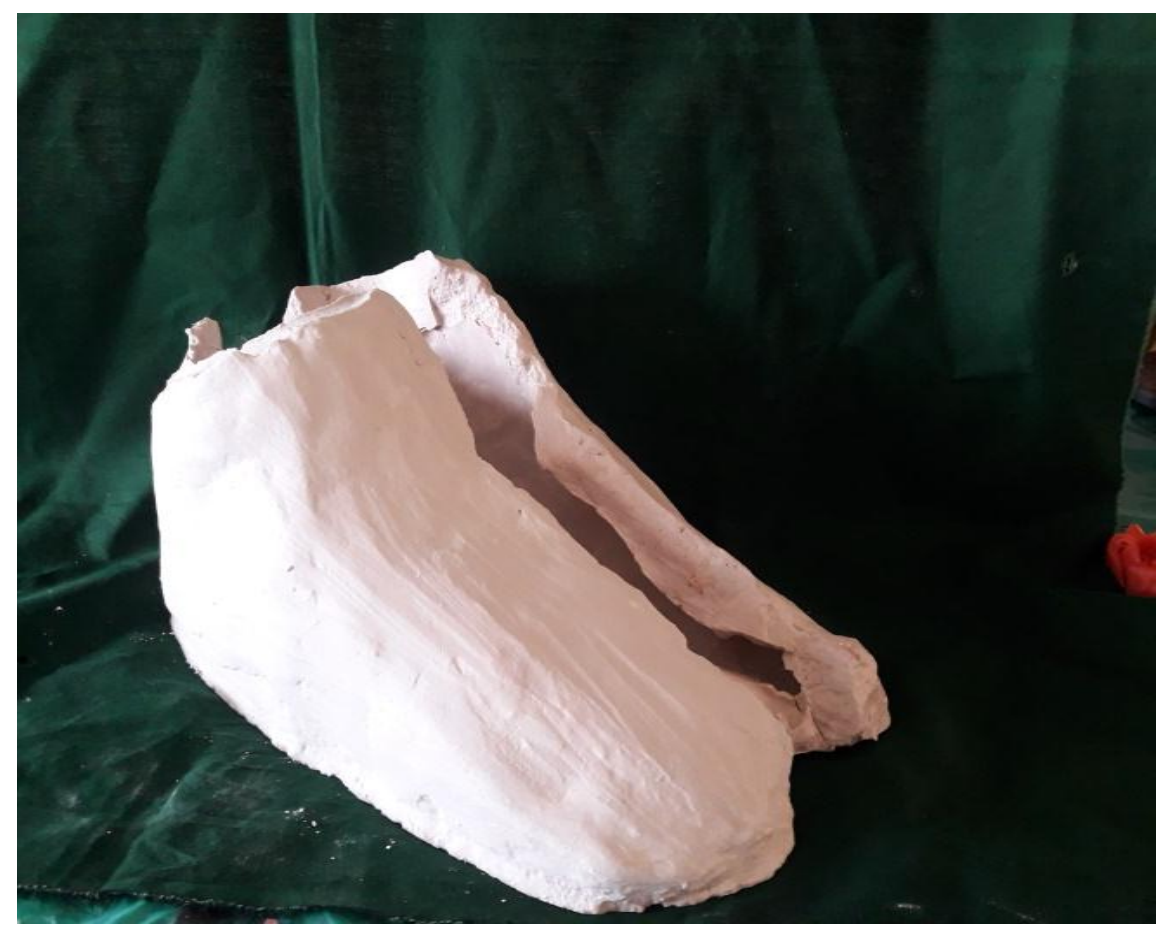

Fig 6:- Plaster mould After Dewaxing.

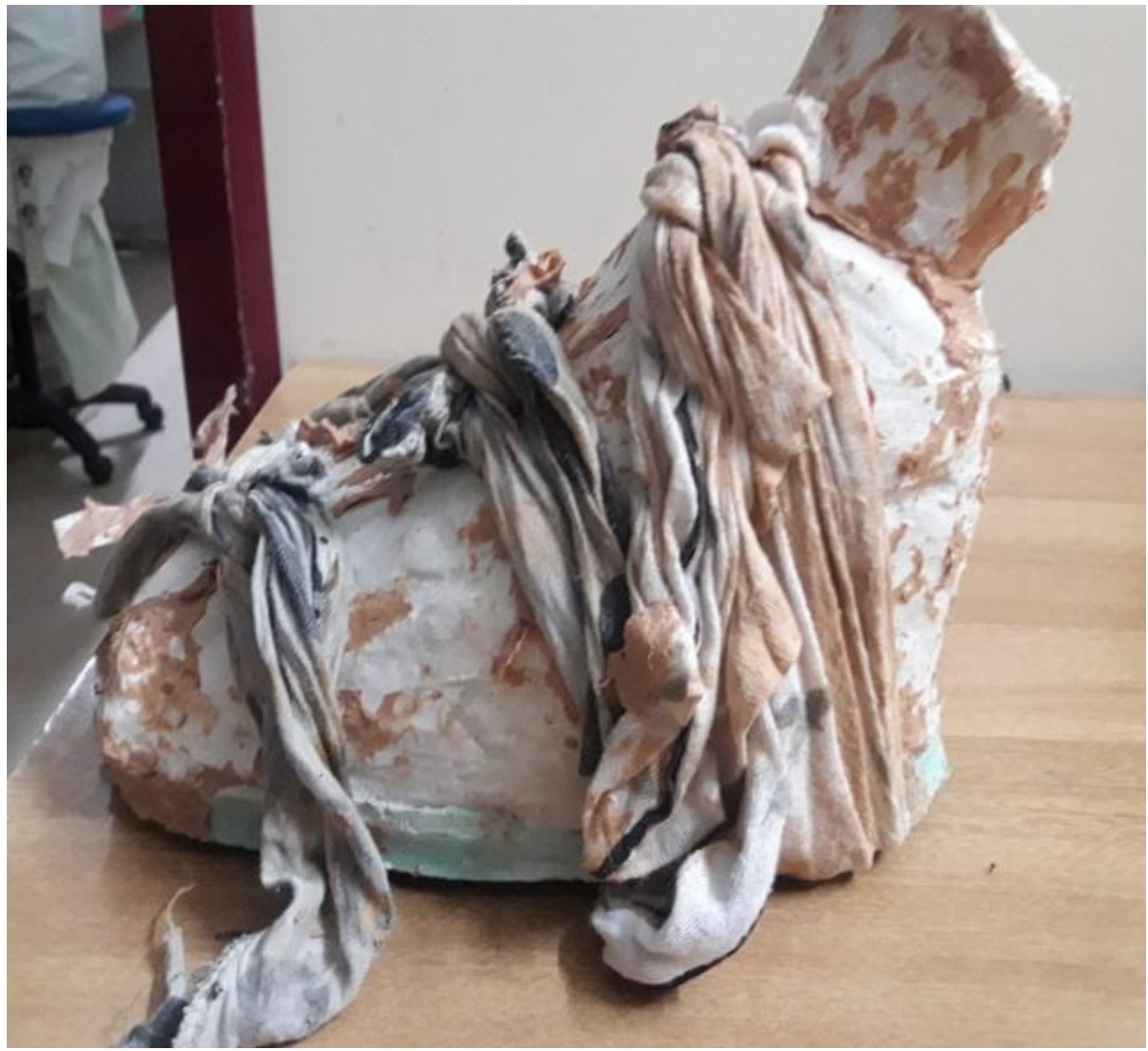

Fig 7:- Plaster Mould Filled With Silicone. 


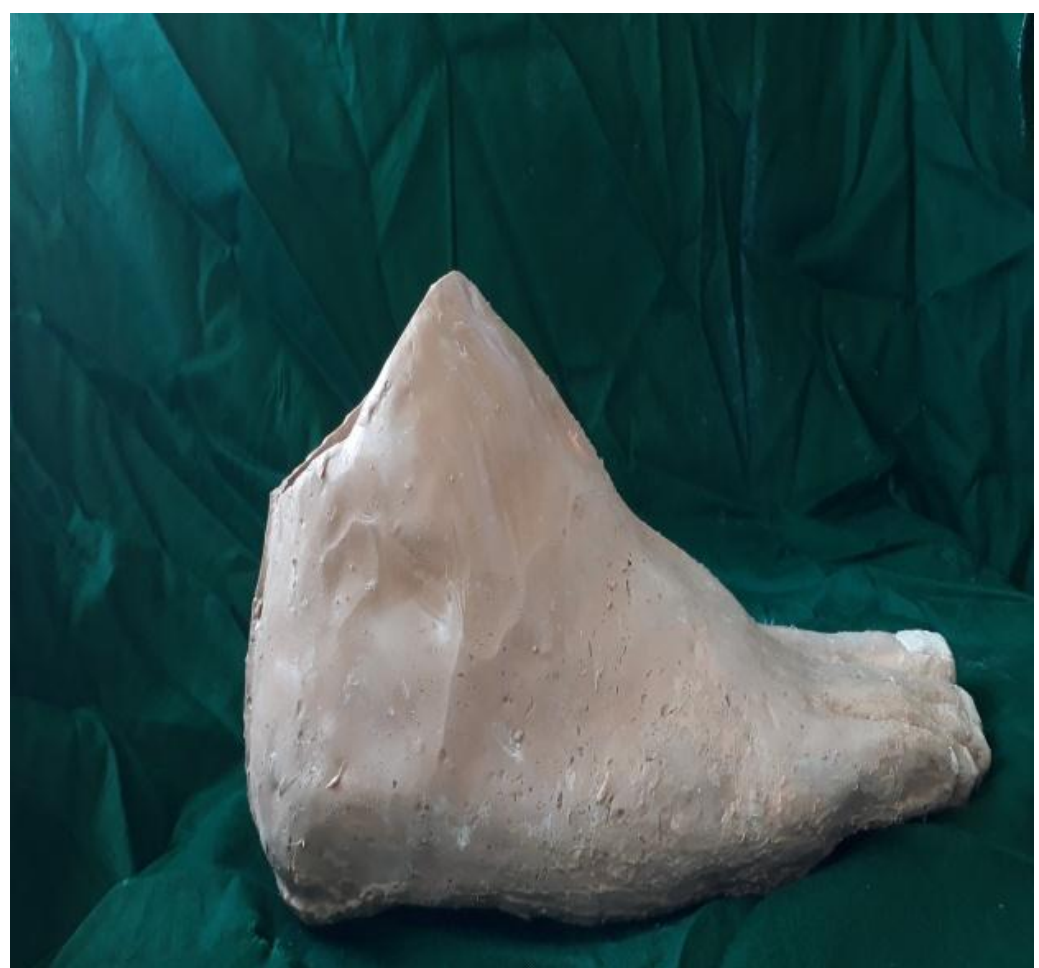

Fig 8:- Silicone Prosthesis.

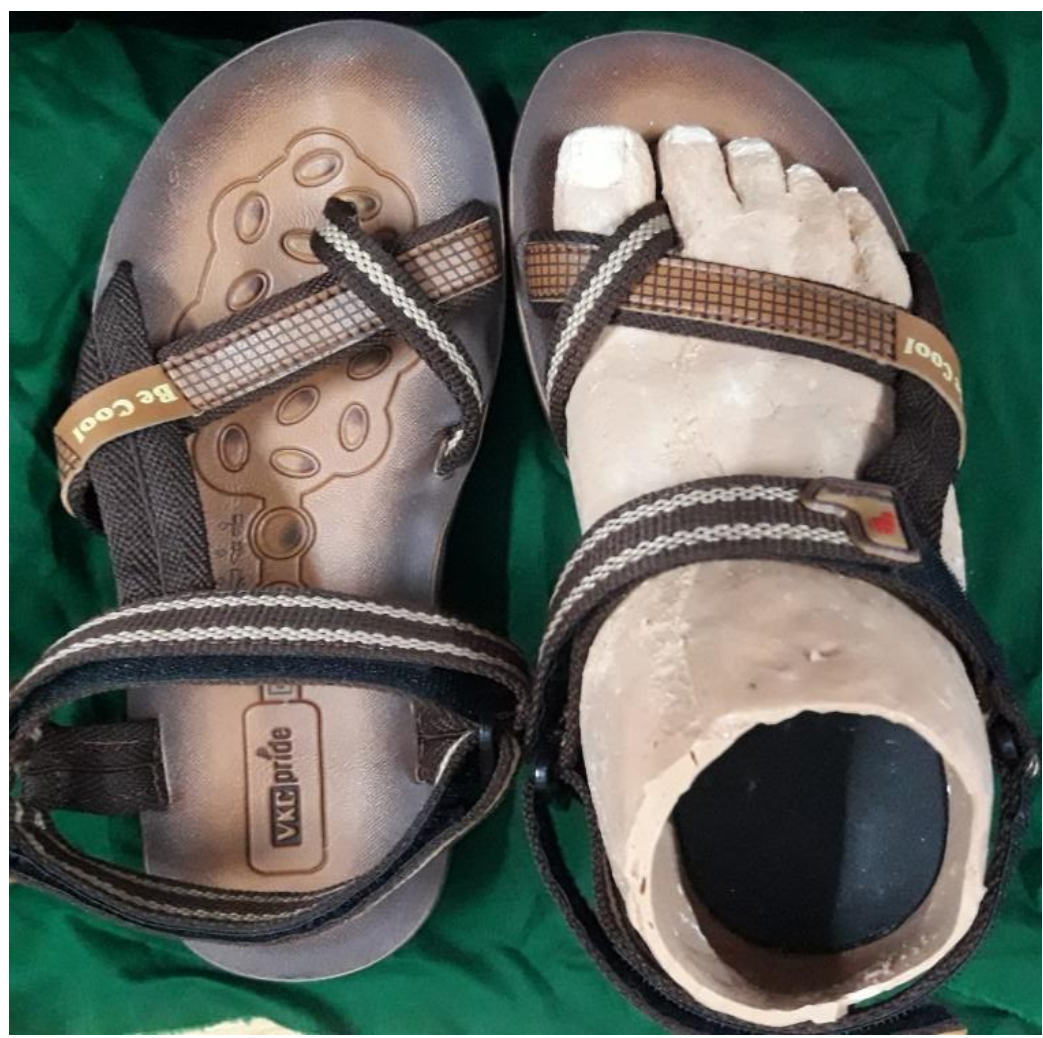

Fig 9:- Silicone Prosthesis Attached With a Foot Wear. 


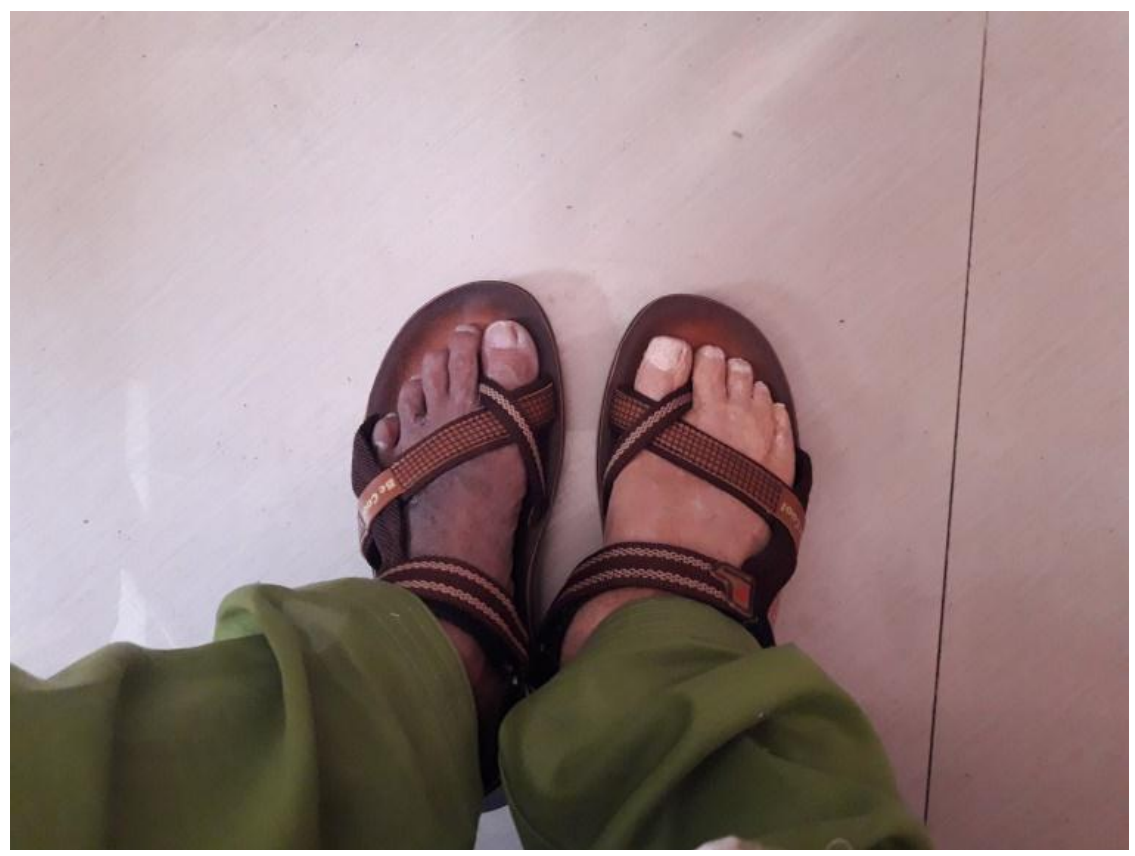

Fig 10:- Silicone Prosthesis Insertion.

\section{Conclusion:-}

Amputation is the final resort done by the medical professionals as a surgical measure to control disease progression. As we see a large number of people facing difficulties to stand independently to carry out their personal needs, we can provide them with a affordable prosthesis so that it may improve their self confidence and give them a second chance.

\section{Acknowledgement:-}

I would like to express my heartful gratitude to my guide Dr Suja Joseph for guding me through every step during the fabrication of the prosthesis.My sincere gratitude to Dr Aby Mathew T,Dr Annie Susan Thomas,DrHaby Mathew Somson,DrAlbinGeo,Dr Rene Kuriakose for encouraging me to finish my prosthesis.It will be incomplete if i don't mention my colleagues Dr RiyaMathew, DrMaymolFrancis, DrAnijaDas, DrAswatiSoman, DrMinnuHarshakumar, DrSaranya Y S for helping and supporting me throughout my work. Lastbut not the least I thank God Almighty to help me finish my prosthesis.

\section{References:-}

1. Dathan PC, Kumar TM, Ravindran S, Nair KC, Kumar A. Prosthetic Rehabilitation of Lower Limb with RTV Silicone Using Prosthodontic Clinical and Laboratory Techniques-A Case Report. Journal of clinical and diagnostic research: JCDR. 2016 Aug;10(8):ZD35.

2. Philbin TM, Leyes M, Sferra JJ, Donley BG. Orthotic and prosthetic devices in partial foot amputations. Foot and ankle clinics. 2001 Jun;6(2):215-8.

3. Yonclas PP, O'Donnell CJ. Prosthetic management of the partial foot amputee.Clinics in podiatric medicine and surgery. 2005 Jul 1;22(3):485-502.

4. Stills ML. Partial foot prostheses/orthoses. ClinProsthetOrthot. 1987;12(1):14-8.

5. Lange LR. The Lange silicone partial foot prosthesis. JPO: Journal of Prosthetics and Orthotics. 1991 Oct $1 ; 4(1)$ :xxiv. 